\title{
Una historia del Frente de Liberación Homosexual y la izquierda en Argentina
}

\author{
Santiago Joaquin Insausti' (iD 0000-0002-0640-145X \\ 'Universidad Nacional Autonoma de Mexico, Instituto de Investigaciones Sociales, \\ Ciudad de Mexico, Mexico. CP: 04510 - difusion.iis@sociales.unam.mx
}

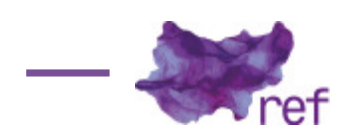

Resumen: Surgido en la década del setenta en Argentina en un clima de radicalización política y dentro del marco de la nueva izquierda, el "Frente de Liberación Homosexual" apostará a una alianza con las organizaciones de izquierda. La investigación analizará diacrónicamente tanto las mutaciones en los discursos políticos y en las estrategias de lucha que se articularon en el diseño de esta alianza como las tensiones y contradicciones que esta propuesta generó en relación con las bases, al interior de la agrupación, y con el resto de las organizaciones militantes.

Palabras clave: frentes de liberación homosexual; nueva izquierda; Argentina.

Uma história da Frente de Libertação Homossexual e a esquerda na Argentina

Resumo: Surgindo durante os anos setenta na Argentina em meio à radicalização política e inspirada pelo surgimento da Nova Esquerda, a Frente de Libertação Homossexual (FLH) tentou uma aliança com as organizações de esquerda. Esta pesquisa visa conhecer, diacronicamente, tanto as mutações no discurso político do FLH e suas estratégias de luta que se articularam no projeto dessa aliança, quanto as tensões e contradições surgidas em relação às bases, dentro do próprio $F L H$, e com as outras organizações ativistas.

Palavras-chove: frentes de libertação homossexual; nova esquerda; Argentina.

A History of the Homosexual Liberation Front and Left-Wing Politics in Argentina Abstract: Emerging during the seventies in Argentina during the political radicalization and inspired by the rise of the New Left, the Homosexual Liberation Front (Spanish acronym FLH) attempted an alliance with a variety of organizations on the left. My research will trace the mutations in the political discourse and strategies shaping the attempts at allying with the left-wing over time, as well as the tensions and contradictions that it created among both the rank and file, within the $F L H$, and other organizations. Keywords: Gay Liberation Fronts; New Left; Argentina.

\section{Introducción}

En 1967, durante la denominada "Revolución Argentina" y en el marco del que hasta en ese entonces era el mayor avance del Estado en la regulación de la sexualidad y de la expresión de género de la población, un grupo de obreros, migrantes del interior del país y sindicalistas del gremio de las telecomunicaciones fundan "Nuestro Mundo". Éste fue el primer grupo de activismo político homosexual latinoamericano, que se nucleará en 1971 junto con otros grupos de intelectuales y activistas en el Frente de Liberación Homosexual (FLH).

Nutridos por la teoría marxista, pero también por el feminismo radical, identificarán la revolución sexual como indisociablemente ligada a la revolución social. En el contexto de la emergencia de la nueva izquierda y en un clima de efervescencia social generalizada, el Frente se identificará con la esperanza de la liberación nacional apoyando -aunque no sin contradicciones- el proceso que culminará con el retorno de Juan Domingo Perón y apostando a una alianza con el peronismo de izquierda.

El objetivo de este trabajo es efectuar un estudio genealógico de esta apuesta, reconstruyendo la historia de "Nuestro Mundo" y del FLH mediante el análisis tanto de las mutaciones 
en los discursos políticos y en las estrategias de lucha que se pusieron en juego en el diseño de esta alianza, como de las tensiones y contradicciones que esta propuesta generó en relación con las bases, al interior del FLH, y con las propias organizaciones militantes.

Frecuentemente, la experiencia del FLH tiende a reconstruirse sincrónicamente a través del análisis discursivo de Somos, la última de sus publicaciones. En cambio, este trabajo abordará también los demás materiales del FLH, analizando sus transformaciones desde una perspectiva histórica. Las estrategias del FLH solo pueden entenderse en íntima articulación con los cambios en el escenario político en el cual pretendían incidir. Las décadas del sesenta y del setenta constituyen un período de profunda conmoción en la política argentina, la cual estuvo sujeta a cambios repentinos que a veces se producían en cuestión de meses. Solo un análisis diacrónico atento a las variaciones en la coyuntura política nacional puede percibir las transformaciones en las estrategias y los discursos políticos de una organización que, lejos de la homogeneidad con la que fue generalmente descripta, se caracteriza por ajustar rápidamente sus tácticas en relación con una coyuntura política altamente voluble.

Con este fin, reconstruiremos la historia, el discurso y las estrategias de estas organizaciones en tres momentos. Primero, basándonos en el análisis de la revista Nuestro Mundo, editada en 1969, se analizará cómo, en respuesta a la dicotomía criminalización/patologización impuesta por la prensa, el grupo se inclina por la primera de las opciones desde una posición victimizante, con fuertes referencias al discurso científico. Segundo, a través del análisis del periódico Homosexuales, editado en 1973, y de las notas publicadas en la prensa masiva, se analizarán las estrategias utilizadas por el FLH para presentarse ante las organizaciones de izquierda como un aliado "digno" y necesario, con un estilo beligerante plagado de referencias a la teoría marxista al tiempo que, paralelamente, tendía puentes en vistas a establecer un diálogo con diferentes reparticiones estatales. Finalmente, ante el fracaso de estos intentos, se investigará mediante la revista Somos el intento de acercamiento que el Frente hace a las bases, recuperando las expresiones de la subcultura de las maricas y sus relatos en primera persona, sentando así las bases de un discurso del orgullo.

Generalmente, las cronologías oficiales del movimiento LGTB argentino tienden a producir dos modelos opuestos y enfrentados. La política de ampliación de ciudadanía que habría caracterizado al activismo homosexual de la década del setenta habría centrado sus políticas en la negociación con el estado a partir de la definición de una identidad homosexual esencial fundada en el discurso del orgullo. De modo antagónico, la política radical del FLH se habría orientado hacia la revolución social, sin reconocer como interlocutores válidos a las agencias del Estado, desde una perspectiva que buscaba la liberación de la sexualidad como un todo sin basamentos en identidades específicas. Un estudio histórico, en cambio, muestra que lejos de adecuarse a estos modelos estancos, el FLH adaptaba sus tácticas políticas, su discurso y su definición sobre la homosexualidad estratégicamente según los diferentes momentos del campo de la izquierda y según las potencialidades y limitaciones que planteaban las diferentes versiones del Estado al que se enfrentaba.

La indagación partirá del análisis de un corpus de documentos diversos el cual se leerá a la luz del análisis de bibliografía secundaria (Flavio RAPISARDI; Alejandro MODARELLI, 2001; Juan José SEBRELI, 1997; Patricio SIMONETTO, 2017, 2017B; Guido VESPUCCI, 201 1, 2017) de la historiografía del período y de trabajos anteriores del autor (Santiago INSAUSTI, 2007, en prensa; Pablo BEN; Santiago INSAUSTI, 2017)). El corpus documental pretendió ser lo más exhaustivo posible y cubrir toda la documentación disponible tanto en su variedad de soportes como de momentos históricos. Como describiremos, el Frente - a mitad de camino entre el grupo de activistas y la red de sociabilidad - no era una organización monolítica, sino que era extremadamente heterogéneo: estaba compuesto por diversas agrupaciones que tenían diferentes líneas internas en tensión. La construcción del corpus pretendió dar cuenta tanto de la diversidad de posiciones como de las transformaciones de estas últimas en los diferentes momentos del Frente. El análisis entrecruzado de documentos históricos a veces contradictorios, producidos en contextos y con fines diferentes, permitió revelar tendencias y caracterizar cada momento histórico del Frente mediante la detección de patrones en la evidencia en contraste con la bibliografía secundaria sobre la historia política del período. El corpus se construyó a partir de la prensa oficial de la organización, sus documentos internos, volantes y panfletos, las entrevistas que brindaron a la prensa masiva, la correspondencia que enviaron a otras organizaciones homosexuales en Estados Unidos, los artículos e informes que sobre ellos publicaban otros medios homófilos extranjeros en Canadá, Estados Unidos, Puerto Rico, Chile e Italia y una serie de entrevistas en profundidad realizadas a los ex activistas Zelmar Acevedo, Sergio Pérez Álvarez, Héctor Anabitarte, Marcelo Benítez y Jorge Giacosa.

\section{La revolución argentina y el surgimiento del activismo homosexual.}

Desde la década de 1940 y hasta principios del siglo XXI, el Estado argentino se dedicó a perseguir con ahínco a los disidentes sexuales. La experiencia de las maricas en ese tiempo fue 
de una vulnerabilidad extrema: el mero tránsito por el espacio público las exponía a la posibilidad de ser detenidas.

Durante la primera presidencia de Perón, la persecución se incrementa, producto de la incorporación a los edictos policiales del inciso 20 "H", utilizado durante los siguientes cuarenta años para perseguir a homosexuales y prostitutas. La represión no cesó durante la denominada revolución libertadora ni con el retorno de los gobiernos democráticos (INSAUSTI, 2015). En 1959, el presidente Arturo Frondizi nombró por primera vez al comisario Luis Margaride, quien se mantendría durante quince años, a través de diferentes gobiernos civiles y militares en la organización de masivas campañas de moralidad.

En su autobiografía, Malva (2011) relata cómo, durante la década del cincuenta, un grupo de maricas se nuclea en Maricas Unidas Argentinas, con el fin de apoyarse para sobrellevar la persecución callejera y la experiencia carcelaria. Esta organización tenía un carácter fundamentalmente mutualista: asistían a las detenidas en la cárcel con contención, ropa y comida y también cuando recuperaban la libertad y se descubrían desalojadas de sus pensiones y despedidas de sus trabajos.

Durante el siglo pasado, las redes de solidaridad fueron vitales para que los homosexuales pudieran sobrevivir el aislamiento y la hostilidad. Sin embargo, fue necesario que se dieran ciertas condiciones para que estas redes empezaran a forjar un pensamiento político y a emerger en el espacio público disputando los sentidos hegemónicos sobre la homosexualidad.

Durante el gobierno de facto de Juan Carlos Onganía la represión, además de tener por objetivo a los homosexuales, se enfocará también en el control de la expresión de género y la moral sexual de toda la población (Valeria MANZANO, 2005). Al contrario del Peronismo, en el cual la represión se había enfocado únicamente en los homosexuales, el "Onganiato" dio lugar a un intento de normalización de las culturas sexuales y genéricas que alcanzaba ahora a mujeres solteras, parejas de novios y "hippies". Si bien las relaciones extramaritales eran vistas como moralmente anómalas, la intervención policial sobre esferas de la vida privada no era entendida como legítima y generaba rechazos. Los homosexuales ya no estaban solos en su lucha contra la represión.

Por otro lado, la erosión de las normas sexuales y de género en la década de 1960 (Isabella COSSE, 2010) se produjo en un momento de creciente polarización políica. Tras la caída de Perón en 1955 y el desmantelamiento del Estado de Bienestar, el disciplinamiento de la resistencia peronista se convierte en la principal preocupación de los gobiernos que siguieron, frente a un movimiento obrero que aumentaba en radicalidad ante la prescripción política.

Luego de la "Revolución Libertadora" y sobre todo durante la "Revolución Argentina", el creciente enfrentamiento del Estado con el conjunto de la sociedad civil hizo que los homosexuales comenzaran a percibir sus problemas con la represión policial como un caso particular de un fenómeno mucho más amplio que afectaba a la sociedad en su conjunto. Así, se esperanzaron con que era posible una recepción empática de sus problemáticas por parte del conjunto de la sociedad.

En este contexto, y en el marco de la efervescencia social y del crecimiento exponencial de las organizaciones militantes, era de esperar que los homosexuales se organizaran bajo la consigna de la "liberación nacional", ilusionándose con la posibilidad de asociarse al resto de las organizaciones sociales en lucha contra la represión estatal. Sin embargo, el camino hacia esa articulación no fue tan fácil como parecía.

\section{Primer momento: El grupo "Nuestro Mundo" y la estrategia victimizante (1967-1971)}

Existe una controversia respecto de cuándo se originó el grupo "Nuestro Mundo". Generalmente, es aceptada la versión de Néstor Perlongher (1997) en su Breve historia de la homosexualidad en Argentina, que sitúa el origen en 1969. Sin embargo, Héctor Anabitarte (2005, 1982), miembro fundador del grupo, sitúa el comienzo en 1967. Esta segunda hipótesis, es respaldada por los materiales legados por la organización. Se conserva un boletín publicado en 1970, que indica que se trataba del tercer año de publicación. En el editorial, se mencionan las dificultades que tenía el grupo para publicar el boletín con regularidad, y señala que el primer número salió en septiembre de 1968. El segundo boletín, de enero de 1974, refiere pertenecer al séptimo año de edición de la publicación, fortaleciendo ambas publicaciones la posición de Anabitarte.

Las efemérides y la construcción de mitos de origen son esenciales para la consolidación de las comunidades políiticas: lo cierto es que el grupo "Nuestro Mundo" no tiene un hito fundacional concreto.

Anabitarte es el único testimoniante que da cuenta de la experiencia de la agrupación. Según él, "Nuestro Mundo" empieza a surgir en el Correo Central, a partir del encuentro de varios delegados homosexuales de FOESIC, el gremio de Correos y Telecomunicaciones. Anabitarte 
cuenta que era imposible discutir el tema de la homosexualidad frente a los compañeros del sindicato, por lo que los pocos miembros homosexuales de FOESIC partían juntos a tomar un café luego de finalizadas las reuniones del gremio. Posteriormente, el grupo empezará a reunirse independientemente.

Los activistas de "Nuestro Mundo" pertenecían mayoritariamente a las clases populares. Además de los militantes de FOESIC, el grupo nucleaba a trabajadores fabriles y jóvenes migrantes del interior del país (ANABITARTE, 2005).

Si bien se trataba de un grupo de activistas con experiencia, en principio no tenían una base teórico-política sólida, sino que se volcaron de lleno a la acción.

Una de las estrategias en la lucha contra los edictos policiales consistía en enviar declaraciones a las redacciones de los diarios denunciando la represión policial, impresas por Anabitarte en los mimeógrafos de la agencia de noticias DAN, donde trabajaba. En una oportunidad, la revista sensacionalista Así les hace una nota y publica una pequeña columna, lo que desencadena un debate al interior de la comunidad homosexual: se temía que la presencia del discurso homosexual en los medios masivos desencadenase más represión.

En 1968, "Nuestro Mundo" empieza a publicar su revista homónima: Nuestro Mundo. Boletín editado por homosexuales de Buenos Aires.

\section{La prensa de "Nuestro Mundo". Objetividad científica y política de la lástima.}

Hacia diciembre de 1970 se editaba el cuarto número de este boletín: un compendio de cinco páginas, sin mayores esfuerzos estéticos, que eran distribuidas de mano en mano. En este ejemplar se puede apreciar un abordaje político muy diferente del que se verá luego en Homosexuales, el periódico del FLH, cuyo primer número será publicado en 1973.

La primera nota presenta un informe de un encuentro científico donde participaron "dos profesores y dos homosexuales varones" (Nuestro Mundo, 1970, p. 1). La nota siguiente, reproducida de la revista Tribuna Alemana, titulada "¿Varón o Hembra?, En búsqueda de la enigmática sustancia $X$ ", relata el descubrimiento de las hormonas que determinan el sexo del feto y ensaya una explicación de la homosexualidad basada en la endocrinología. A continuación, otra nota informa que un hospital porteño se encuentra reclutando homosexuales para probar una nueva droga, hasta ahora solo probada en animales. La droga en cuestión reduciría la libido y permitiría controlar el deseo sexual "cuando este se descontrola" (Nuestro Mundo, 1970, p.3). A continuación, otro artículo, citado del Times de Nueva York, refiere a la apertura por parte de Harry Benjamin de un centro médico para el diagnóstico y el tratamiento de la transexualidad que ya habría realizado varias operaciones de cambio de sexo. Con estos artículos, Nuestro Mundo pretendía legitimarse mediante la referencia a una supuesta objetividad científica, en contraposición a los discursos homofóbicos, contrapuestos y tildados de prejuiciosos e infundados.

El recurso, además, de alguna manera exculpa y justifica a los homosexuales: nadie puede ser culpado por sus afecciones. En palabras del descubridor de la misteriosa sustancia X: "(los homosexuales) serían tan poco dignos de castigo como el enfermo de tuberculosis o de cáncer" (Nuestro Mundo, 1970, p.4).

Por otro lado, el discurso en primera persona se construía apelando a la experiencia del "sufrimiento" de los homosexuales. Este también se expresa en un artículo tomado de la revista Siete Días sobre una película titulada Miserias y esplendores, en la cual el director, Vittorio Caprioli, era presentado como un ser compasivo porque se había inspirado en la historia de "un travesti"[sic], así descripto: "Lulú era viejo, infeliz, estaba cansado". Al observar esta tragedia, Caprioli había decidido esbozar la historia de Alessio, "un homosexual que había sido bailarín de revista. Un hombre solitario e infeliz" (Nuestro Mundo, 1970, p.2). En otra nota, se reproduce la crítica de otra película efectuada por la prensa: "El trágico drama de dos mujeres que se amaban y no podían dejar de destruirse... Una obra dramática, profunda y densa que desnuda las más íntimas miserias humanas" (Nuestro Mundo, 1970, p.3).

El objetivo de este discurso era generar 'compasión' ante la "capacidad humana" de los homosexuales, como si se pretendiera fomentar mediante la exposición de esta empatía, un sentimiento equivalente en el conjunto de la sociedad.

Si bien la mayoría de los artículos había sido extraída de diferentes revistas, la selección de las notas trasluce el contenido ideológico de la agrupación, profundamente permeado por los discursos hegemónicos en la prensa escrita.

Es interesante analizar el mecanismo de citación que estas primeras "comunidades sufrientes de homosexuales" (Ernesto MECCIA, 2017) realizan de los discursos de la prensa, los cuales constituían, de un modo o de otro, los únicos sentidos socialmente disponibles para darle sentido a sus deseos y sus prácticas.

Es necesario sin embargo entender el uso estratégico que se hacía de estos discursos. En el período estudiado, dos modelos de noticias imperaban en la prensa escrita. Por un lado, las 
noticias policiales que relataban monstruosos crímenes cometidos por homosexuales, representados como una amenaza que ponía en jaque a la sociedad. Por otro lado, las revistas de información, que, embebidas del discurso médico-positivista y desde una perspectiva pedagógica, explicaban las causas fisiológicas y los padecimientos de los homosexuales. Mientras que el primero de los discursos los construía como peligrosos criminales responsables de su degeneración, el segundo los consideraba víctimas sufrientes que debían ser comprendidas en su dolor. En la perspectiva de los integrantes de "Nuestro Mundo", abrazar el segundo de los paradigmas, haciendo suyo el discurso de la ciencia y la perspectiva victimizante, podía convertirse en un instrumento para enfrentar los discursos monstruosos que los constituían como blanco del aparato represivo, en un contexto en el cual la violencia material y simbólica no permitía aún la emergencia de discursos plenamente reivindicativos.

En 1969 los activistas de "Nuestro Mundo" entran en contacto con el escritor Juan José Hernández que los conecta con la elite ilustrada porteña y con las luchas de las minorías sexuales y étnicas estadounidenses. De hecho, Anabitarte cuenta cómo el viaje a Nueva York de Hernández posibilitó que el grupo, conformado por trabajadores de clase media-baja sin formación intelectual, empezara a pensar de un modo radicalmente diferente, que devendría luego en la fundación del FLH, ya no desde una perspectiva reivindicativa, sino desde el discurso de la liberación. Hernández, en Estados Unidos, entra en contacto con el grupo radical negro "Panteras Negras", con quienes continúan en contacto varios años después (RAPISARDI; MODARELLI, 2001, p. 143-144).

"Panteras Negras" fue una organización política afroamericana y anticapitalista, heredera de las ideas de Malcom X, que incitaba a la población negra a armarse para defenderse de la persecución policial. Nuestro Mundo traduce la "Carta del comandante del partido Panteras Negras a los hermanos y hermanas revolucionarios sobre los movimientos de liberación femenina y homosexual" (Huey NEWTON, 1997), un documento extremadamente progresista y fundamental para la organización, que circulará internamente para recién ser publicado cinco años más tarde como una de las notas centrales de Homosexuales, el primer diario del FLH.

La carta es elocuente: en ella, Huey P. Newton, uno de los más importantes líderes del "Black Power", llama enfáticamente a aliarse con los movimientos feministas y de homosexuales, y exhorta a abandonar toda forma de discriminación.

Curiosamente, las Panteras Negras influyen de manera mucho más determinante en los activistas de Nuestro Mundo que los grupos de liberación sexual norteamericanos, envalentonados por las revueltas de Stonewall. ' De hecho, Anabitarte recuerda que la revuelta neoyorquina pasa desapercibida para Nuestro Mundo, más enfocados en la búsqueda de elementos que les permitieran dar cuenta de la ligazón entre el activismo homosexual y la militancia sindical.

Años más tarde, la politización creciente del FLH y el manejo teórico de algunos de los activistas que provenían del grupo Profesionales y del grupo Eros, permitieron que terminara de reformularse esta identificación con el resto de la sociedad, ya no en términos de víctimas que sufren sino positivamente, como luchadores contra un régimen político autoritario y un sistema social opresivo.

\section{1 - El Frente de Liberación Homosexual}

En 1969, a través de Hernández, el grupo Nuestro Mundo tendrá contacto con un grupo de intelectuales porteños entre los que se encontraban Manuel Puig, Blas Matamoros y Juan José Sebreli. Estos empiezan a reunirse por separado en 1970 junto a otros intelectuales en el grupo Profesionales, junto al cual, Nuestro Mundo funda el FLH, en agosto de 1971.

A partir de ese momento la opresión sexual será conceptualizada como indisociablemente ligada a la opresión social, y la liberación dependerá necesariamente de la alianza con el resto de los movimientos sociales.

Ese mismo año, en la Facultad de Filosofía y Letras de la UBA, surge el grupo Eros bajo el liderazgo de Néstor Perlongher, quien había abandonado la agrupación Palabra Obrera, ${ }^{2}$ luego de que esta rechazara su pedido de incorporar la liberación homosexual dentro de su programa político. Eros se incorpora al frente en marzo de 1972 (Somera Cronología del F.L.H, S/D).

\footnotetext{
'Si bien Stonewall fue importante para Néstor Latrónico, activista argentino que participo del Gay Liberation Front neoyorquino antes de retornar a Buenos Aires e incorporarse al FLH en 1973 (SIMONETTO, 2017) en el testimonio de Matamoros, Benítez o Anabitarte que venían participando desde años antes, Stonewall tiene una importancia menor. Javier Galeano (en prensa) analiza la correspondencia intercambiada entre las organizaciones argentinas y norteamericanas demostrando el pocointerés mutuo. Galeano, describe como "Ios activistas argentinos eligieron aquellos interlocutores y modelos de activismo que respondían mejor a sus experiencias y cultura política". La perspectiva de la "liberación nacional" era el principio organizador de toda la políitica del así llamado "campo popular" a principios de los años setenta. Dado que la contraposición con el "imperialismo yanqui" era el eje articulador de esta perspectiva, resulta esperable que el reconocimiento de las efemérides norteamericanas fuera acotado, privilegiándose los diálogos y la construcción de redes regionales (SIMONETTO, 2017).

2 Palabra Obrera fue una agrupación trotskista fundada en 1964 que, en consonancia con su participación en las elecciones de 1983 pasara a denominarse Partido Obrero, nombre con el cual subsisten en la actualidad.
} 
Los documentos señalan que, con el objetivo de captar militantes, se hacían grandes reuniones de información por donde desfiló buena parte del ambiente gay porteño (PERLONGHER, 1997). Los encuentros en general tenían lugar en casas particulares, donde se explicaba la línea política general del FLH. Los interesados se incorporaban al Grupo de Concientización, llamado Alborada, desde donde pasaban luego a formar parte de los diferentes grupos que se fueron creando.

Los grupos tenían cada uno su identidad política, se reunían por separado y delineaban sus modos de funcionar de forma autónoma. Las reuniones conjuntas fueron pocas, dada la imposibilidad que existía en ese momento para organizar reuniones numerosas. Sin embargo, los grupos se contactaban permanentemente con el fin de organizar acciones conjuntas 0 de consensuar documentos.

Nuevos grupos se suman al Frente: Safo, un grupo conformado por mujeres lesbianas, que no llegó a tener un gran número de participantes; ${ }^{3}$ Bandera Negra, escindido de Eros por su acercamiento al anarquismo; Alborada, con un interés en generar "concientización"; y también tres grupos de carácter religioso, uno de católicos, compuesto fundamentalmente por ex seminaristas que aspiraban a la aceptación papal de la homosexualidad; otro grupo compuesto por tercermundistas; y finalmente, un grupo de cristianos protestantes (Somera Cronología del F.L.H, S/D).

Los principales grupos del FLH, Nuestro Mundo, Profesionales y Eros, tenían características muy diferentes. En términos de clase, Nuestro Mundo era de extracción obrera, en general de sindicalistas con una larga tradición de activismo político. Eros estaba constituido por estudiantes de clase media, generalmente de la Facultad de Filosofía y Letras y asociados a partidos de izquierda, mientras que Profesionales estaba integrado por escritores de reconocida trayectoria.

Desde un principio, la articulación de los grupos fue conflictiva. El Frente logró hacerse rápidamente conocido en el mundo de los homosexuales, pero, aunque muchas personas participaban, solo aquellas que estaban altamente politizadas y tenían una perspectiva radical permanecían en él. De hecho, en una carta enviada en 1975 el Frente consigna la aparición en Tucumán de un grupo de homosexuales que se autoproclamaba "pro-capitalista" y que criticaba al FLH por ser demasiado radical (Body Politics, 1975). Según Perlongher, esta radicalización: "espantó del Frente a los homosexuales burgueses: el movimiento siempre fue extremadamente pobre, sin recursos materiales, e integrado en su mayoría por gente de clase media y media baja, con algunos proletarios y lúmpenes" (PERLONGHER, 1997, p.79).

Otra perspectiva sobre este proceso de radicalización la aporta Juan José Sebreli. Profesionales, conformado en su mayoría por escritores, estaba en recurrente tensión con el grupo Eros:

Al principio éramos todos intelectuales. Se intentó hacer una cosa muy ambiciosa, que quedó en la nada porque el militantismo lo arruinó todo. Ese afán de estar con los guerrilleros y con la moda (...) Se discutían ideas, se pretendía hacer una tarea de elaboración teórica de esclarecimiento... Pero el militantismo de la época no lo permitía. (Patricio LENNARD, 2009)

Esta polarización entre la radicalidad del grupo Eros y Profesionales, más moderado y menos combativo, tensiona al Frente en estos primeros años. En 1971 Sebreli, Matamoros, Hernández y Puig tenían casi todos más de cuarenta años y ya eran escritores reconocidos en el ambiente intelectual porteño. Sebreli había participado de revistas culturales de la talla de Sur y Contorno y había escrito varios años antes su best-seller, Buenos Aires, vida cotidiana y alienación (1964). Puig ya había publicado con muy buena recepción La traición de Rita Hayworth en 1968 y Boquitas pintadas en 1969, Matamoros tenía publicados cuatro ensayos, y Hernández, cinco libros de poesía. Perlongher, por su parte, era un estudiante tozudo e idealista de apenas veintidós años, que recién empezaba a estudiar Sociología, y que se debatía entre el Frente, las clases y las asambleas de la Facultad.

En el otro extremo del espectro ideológico se encontraban los grupos religiosos. De uno de estos grupos se conservan dos documentos en los cuales las diferencias con el resto de los grupos del FLH saltan a la vista: el grupo de católicos se autodenomina Club, y dice tener presidente, comisión directiva y aspirantes a ingreso, lo que contrasta con el horizontalismo del Frente.

Además, siguen sosteniendo el discurso propio de los primeros años de Nuestro Mundo, de posición cientificista y lastimera: en este documento, por ejemplo, se señala que la homosexualidad es una exteriorización genuina de la personalidad, de la cual el homosexual no puede ser culpado, ya que no se trataría de una elección (Grupo Católicos, S/D).

Sin embargo, a pesar de la heterogeneidad del frente, que contenía a militantes de un amplísimo abanico de posiciones ideológicas, las posiciones de izquierda eran hegemónicas, lo que muchas veces planteaba dificultades con el trabajo en las bases. Anabitarte señala:

En Nuestro Mundo éramos gente de izquierda, y en el resto de los grupos esta era la posición mayoritaria lo que muchas veces nos limitaba: los gays muchas veces tenían que asumir no solo

${ }^{3}$ El FLH estaba compuesto mayoritariamente por varones homosexuales. En una comunicación personal, Sara Torres me comento que el grupo Safo estaba conformado solamente por tres personas. 
que había un frente de homosexuales reivindicativos sino que también era marcadamente de izquierda. ${ }^{4}$

El funcionamiento federativo en células autónomas posiblemente permitió que el Frente pudiera contener a un amplio universo de activistas provenientes de trayectorias políticas y de tradiciones ideológicas diferentes -y hasta incompatibles-, aunque congregados en la lucha contra la represión policial, lo que no quitaba que la identificación con la izquierda estuviese exenta de tensiones tanto entre los grupos al interior del frente como en la relación de los activistas con las bases.

\section{Segundo momento: La búsqueda de la empatía y las políticas de seducción a la izquierda. (1971-1974)}

En marzo de 1971, el debilitamiento de la Revolución Argentina, producto del clima insurreccional generalizado - dentro del cual el Cordobazo tiene un papel preponderante- provoca la caída de Onganía y el ascenso de Lanusse, quien asume con el objetivo de trazar una salida política a la dictadura, a través de un acuerdo con las principales fuerzas políticas. En este marco, la persecución política y la represión policial disminuyen.

Para el Frente, la apertura implicó un incremento del número de militantes y un salto tanto en términos de la consolidación ideológica como en relación con el desarrollo de la actividad militante. En el aspecto táctico, la lucha estaba centrada en el reclamo por la eliminación de los edictos policiales. Estratégicamente los documentos conjuntos del FLH comienzan a ligar la represión sexual al capitalismo, denunciando que el modelo de familia heterosexual era un modo de reproducir las jerarquías sociales. Se explica que la transformación profunda de la estructura no puede llevarse a cabo sin terminar con la opresión sexual que al mismo tiempo oprime a heterosexuales y homosexuales.

Desde 1972, en el Grupo de Política Sexual, el grupo Eros del FLH entabló un diálogo muy productivo con la Unión Feminista Argentina y el Movimiento de Liberación Feminista, las primeras organizaciones feministas que emergían a inicios de los años setenta (BELLUCCI, 2014). En los documentos del grupo, influenciados por las lecturas de Engels, del freudomarxismo de Reich y de Marcuse y de feministas radicales como Firestone se advierte un doble movimiento. Mientras que por un lado se pretendía naturalizar la homosexualidad rastreándola universalmente en diferentes sociedades y culturas (Homosexuales, 1973), la familia era denunciada como histórica y contingente en su carácter de aparato ideológico del Estado (VESPUCCI, 201 1, 2017).

En ese año comienza "un gran período de propaganda por medio de volantes que son arrojados en lugares públicos" (Somera Cronología, S/D). Se trataba, en realidad, de cartulinas de colores, recortadas en formas llamativas, que llevaban escrito a mano alzada una consigna disparadora "El mismo sistema que te oprime y explota es el que nos discrimina a nosotros" 0 "Cordobazo, Rosariazo, HOMOSEXUALAZO!!!". Es claro el intento de capitalizar el rechazo generalizado a la dictadura, fomentando la empatía con la causa homosexual mediante el recurso de equiparar la represión a los homosexuales con la represión política.

En septiembre de 1972 se inaugura la presencia del FLH en los medios de comunicación: algunos activistas se encontraban pintando el grafiti "Lesbiana no estás sola", cuando fueron agredidos por la policía. El hecho mereció un comunicado del FLH que fue enviado a todos los medios de prensa. Anabitarte cuenta: "Como en ese período era muy alto el disgusto con la represión policial y militar, el comunicado de prensa del Frente denunciando la agresión fue levantado por un amplio abanico de medios: desde el supersensacionalista diario Crónica hasta La Opinión." (Steve FORGIONE, 1982). Notamos de nuevo como la universalización de la represión genera, en la perspectiva de los homosexuales, un ambiente propicio para la empatía.

Exactamente un mes antes, en agosto de 1972 se publicaba la primera entrevista al FLH por parte de un medio de comunicación. La nota, titulada "Homosexualidad, las voces clandestinas" es publicada en la revista Panorama, de gran tirada en ese momento. En ella denuncian la represión, desmitifican algunas creencias pseudocientíficas sobre la homosexualidad y declaran el interés de relacionarse con los partidos de izquierda para buscar coincidencias. La nota, de carácter sensacionalista, no escatima en imágenes caricaturizadas para asociar al FLH con los grupos guerrilleros: relata cómo en un contexto de hipersecretismo el periodista fue conducido encapuchado hasta un chalet, donde fue recibido por dos activistas del FLH también encapuchados. La nota se ilustra con una foto de dos personas con el puño en alto cubiertas con pasamontañas, tras un estandarte del FLH, en una actitud similar a las fotos que publicitaban las organizaciones guerrilleras. También señalan "tener una organización similar a la de los grupos guerrilleros" basada en "grupos celulares, columnas y un "Presidium Supremo"5 (Panorama, 1972).

El FLH empezaba a enviar señales a las organizaciones de izquierda en la búsqueda de la empatía que imaginaban posible ante la realidad del enemigo común.

\footnotetext{
${ }^{4}$ Héctor Anabitarte, entrevistado por Santiago Joaquín Insausti, Buenos Aires, 5 Sept. 2006.

${ }^{5}$ En referencia al Presidium del Soviet Supremo, órgano de gobierno de la URSS.
} 
En El beso de la mujer araña, Puig (1976), que había participado del grupo Profesionales, representa la apuesta del Frente. La represión hermana a la marica y al guerrillero detenido. Ambos comparten una celda en la prisión: uno como producto de la represión política, el otro por la represión sexual. El guerrillero llega a enternecerse por el homosexual que logra romper la coraza de su masculinidad militante construida alrededor de la racionalidad y la valentía; y el homosexual comienza un proceso de politización que culminara con su involucramiento con la militancia.

La novela plasma de manera alegórica el sueño del FLH: la experiencia común de la represión debía generar en los militantes populares empatía hacia "la loca", al mismo tiempo que debía politizar a las masas de maricas. Ambos debían comprender que las bases de la opresión que sufrían eran las mismas, y que, por lo tanto, los caminos para la liberación eran mutuamente indisociables. Sin embargo, la izquierda estaba muy lejos de experimentar esta empatía.

\section{3 - La esperanza de la liberación: La apuesta al peronismo.}

En 1973, el triunfo del peronismo y el inminente retorno de su líder, detrás del cual se enconlumnaba la inmensa mayoría de las fuerzas políticas, supone un desafío para la cohesión del FLH. Por un lado, los activistas más jóvenes y el grupo Eros, creían que el Frente no podía quedar al margen de un proceso que aunaba a la inmensa mayoría de las fuerzas progresistas. Por otro, una parte importante de los activistas (LENNARD, 2009) desconfiaba del peronismo: no se debe olvidar que el primer y el segundo gobierno de Perón habían inaugurado la represión a los homosexuales instalando las razias y las detenciones a un nivel sin precedentes en la historia argentina.

A pesar de las diferencias, la posición que sostenía acercarse al peronismo se vuelve hegemónica dentro del Frente. Contribuye a esto que, luego de la asunción de Héctor Cámpora, la represión policial a los homosexuales prácticamente desaparece (ANABITARTE, 2006), inaugurándose una "primavera" de dos meses en los que las maricas se manifiestan y son recibidas ante instancias del Estado a las cuales era impensable acceder durante la dictadura.

Así, partir del triunfo del FREJULI el 11 de marzo de 1973, el FLH empieza una serie de acciones que persiguen el objetivo tanto de acercarse a la izquierda peronista mediante la entrevista con algunos líderes militantes, como de iniciar un diálogo con el Estado, el cual es reconocido como interlocutor válido, y al cual se logra acceder de un modo impensado meses antes.

Hay que recordar que el regreso de Perón logra aunar a la inmensa mayoría del arco político. Al mismo tiempo, todos estos sectores, incluidos algunos de la iglesia, se aglutinan en contra de la represión estatal, principal enemigo de los homosexuales. Frente a esto, la apuesta estratégica al peronismo no adolecía de falta de lógica.

Contrariamente a algunas representaciones del sentido común que imaginan al FLH en las antípodas de las políticas de ampliación de ciudadanía, en este período dedicó todas sus fuerzas a intentar incidir en las políticas públicas mediante acciones de lobby. Inmediatamente después de las elecciones, en marzo de 1973, el FLH elaboró una carta modelo que sería enviada a los flamantes diputados del FREJULI (Carta a Diputado, 1973). En este texto se explicaba la vinculación que el Frente establecía entre la opresión sexual y la explotación capitalista, así como también la imposibilidad de llevar a cabo el proceso de liberación nacional sin terminar con la represión policial a los homosexuales.

Al mes siguiente, un memo del grupo Profesionales reporta una entrevista con el diputado Hector Sandler y la urgencia de consensuar un documento apoyando al gobierno de Cámpora que ya había sido aprobado por Eros y Nuestro Mundo. Este documento nuevamente sintetiza la estrategia más general de derrocamiento del sistema social y la táctica de eliminación de los edictos policiales:

El FLH considera que el cambio de actitud social, frente a la homosexualidad, dependerá del grado de organización de los homosexuales y su inserción en las luchas populares; conscientes de que no puede haber liberación sexual sin liberación social y viceversa. (Homosexuales, 1973, p. 3)

El FLH debuta en una manifestación pública en Plaza de Mayo con la asunción de Cámpora. Un grupo de activistas llevaban un cartel que decía "Los putos con Perón" en medio de una enorme movilización que luego se dirigió a liberar a los presos políticos de manera espontánea. Ese año, además, participaron de la masiva marcha a Ezeiza, de la marcha por el aniversario de la masacre de Trelewy, de las concentraciones en repudio al derrocamiento de Salvador Allende (Panorama, 1974).

La vuelta de Perón luego del exilio fue un acontecimiento de gran magnitud en la historia argentina. La participación en el evento desató violentas discusiones entre los grupos, que pusieron en evidencia que el apoyo al régimen no estaba consensuado. Anabitarte señala:

Néstor tenía una posición, Sebreli otra, yo otra.. Ahí empiezan a existir las polémicas.. Cuál tiene que ser la estrategia, porque, por ejemplo el Frente decide ir a Ezeiza a recibir a Perón, pero una parte importante del Frente no estaba de acuerdo, ahí fue Néstor el que más presionó. Néstor no 
era peronista, pero en ese momento estaba la idea medio ingenua y medio tonta de que Perón era como Mao Tse-Tung y que volvía y hacía la revolución, pero después volvió con López Rega (...) Los intelectuales no estaban de acuerdo: ni Sebreli, ni Blas Matamoros ni Juan José Hernández.. el que más lo planteó fue el grupo Eros, que era la gente más joven que presionaba más.. y en "Nuestro mundo" no estábamos de acuerdo, pero fuimos más disciplinados. Yo fui a Ezeiza, pero sin estar convencido de que eso era oportuno, pero Néstor planteaba la importancia de la visibilidad y la importancia de que las fuerzas de izquierda nos vieran, pensando ingenuamente que eso iba a permitir un reconocimiento a la hora de negociar con ellos. ${ }^{6}$

Finalmente, una columna del frente participa de la marcha, confirmando no solo el apoyo al gobierno peronista, sino incluso a Perón mismo como líder y a la imagen simbólica de Evita, a la cual citaban en la pancarta: "Para que reine en el pueblo el amor y la igualdad".

Al mes siguiente, se apelaba nuevamente al Ministerio del Interior para hacer lobby contra la represión policial (Homosexuales, 1973, p. 1). En conjunto, estas políticas mostraban una línea contradictoria que a veces pedía confiar en la capacidad de lucha de las masas pero que rápidamente caía en formas de lobby a diferentes instituciones estatales que pretendían poder cooptar para la lucha de los homosexuales.

\section{El periódico Homosexuales}

El periódico Homosexuales, editado en septiembre de 1973, fue uno de los instrumentos diseñados para presentarse ante el gobierno peronista y ante las organizaciones de izquierda.

A diferencia del boletín Nuestro Mundo o de Somos -último órgano de difusión del FLH-, el periódico Homosexuales estaba dirigido a un lector no necesariamente homosexual: prueba de la magnitud del proyecto y de las pretensiones de masividad es su tirada de cinco mil ejemplares. De hecho, el periódico fue difundido entre los diputados y senadores recientemente electos, entre los funcionarios estatales y entre los activistas populares, con los que tenían contacto, además de ser vendido en algunos puestos de diarios y enviado a organizaciones del exterior (Quinta Rueda, 1972, p. 2). Los artículos pretendían seducir a distintas facciones políticas con los cuales se querían tejer relaciones, al tiempo que contestaban los argumentos homofóbicos más recurrentes de los militantes populares.

Las primeras notas presentaban al FLH describiendo sus acuerdos programáticos y argumentando la inconstitucionalidad de los edictos policiales.

Dos artículos redactados por Profesionales brindaban elementos para confrontar las interpelaciones homofóbicas: una nota sobre la ausencia de represión a la homosexualidad en la antigua Mesopotamia probaba las raíces históricas de la opresión; otra, titulada "Homosexualidad y machismo", ligaba las causas del machismo al capitalismo contemporáneo. Finalmente, un apartado sobre el Informe Kinsey argumentaba el carácter natural e inevitable de la homosexualidad en la especie humana a través de la historia.

La prensa efectuaba un explícito guiño al peronismo: se reproducía un volante repartido en la marcha a Ezeiza con la mencionada cita de Evita, se notificaba de la participación en la concentración en apoyo de Cámpora y se celebraba en otra su triunfo en las elecciones. Al mismo tiempo daba cuenta de su fe en el proceso eleccionario y en las instituciones estatales, al publicar un petitorio al Ministerio del Interior pidiendo la derogación de los artículos represivos y una carta enviada a los comisarios de la Capital Federal en la cual se los instaba a abandonar la persecución a los homosexuales. Un artículo de un grupo norteamericano de homosexuales católicos proporciona elementos para responder a las críticas de la iglesia y para intentar seducir a sus sectores más progresistas. Finalmente, dos artículos tomados de los movimientos de minorías raciales norteamericanos enfatizaban la necesidad de una alianza: en primera plana, la ya analizada carta de las panteras negras probaba que la alianza era tan necesaria como posible, en la última, un volante de un grupo de homosexuales negros de Nueva York cuestiona a los activistas revolucionarios que optaran por seguir desconociendo la lucha de los homosexuales:

Ustedes que se llaman revolucionarios no se han enfrentado a sus actitudes sexistas. En cambio se han aferrado al machismo y en consecuencia al papel del opresor. (...) Por vuestra lucha contra-revolucionaria para mantener (y forzar) la heterosexualidad y el núcleo familiar ustedes perpetua las viejas ideas remanentes del capitalismo. Por vuestra posición anti-homosexual han usado las armas del opresor convirtiéndose en agentes del mismo. (Homosexuales, 1973, p.3)

Este discurso de seducción dirigido a las organizaciones populares también se plasmó en las tres entrevistas publicadas en la prensa masiva. En ellas, sofisticados análisis teóricos de la represión sexual basados en el freudomarxismo se alternaban con arengas en las cuales se convocaba a luchar por la liberación nacional. Pero este discurso, atractivo para los militantes de las organizaciones, caía muchas veces en la trampa de resultar extraño a las bases de homosexuales. A muchas de las maricas, la mayoría de las cuales no estaban politizadas ni

${ }^{6}$ Héctor Anabitarte, entrevistado por Santiago Joaquín Insausti, Buenos Aires, 5 Sept. 2006. 
tenían una base intelectual que les permitiera decodificar las entrevistas, el mensaje les resultaba críptico y ajeno. De hecho, para algunas de las locas que entrevisté en estos últimos años, que en aquel momento pertenecían a sectores populares y se dedicaban a trabajos informales en el rubro de la peluquería o de la confección textil, el FLH, de cuya existencia muchas se enteraban por los diarios, era un fenómeno de intelectuales citadinos de clase media, muy celebrable, pero del cual no se sentían empoderadas de participar.

Finalmente, las estrategias de seducción a la izquierda se evidencian infructuosas. La relación con el peronismo, al igual que con la izquierda, estuvo plagada de contradicciones. Cercana a la posición de la derecha conservadora, que identificaba a la homosexualidad como una degeneración moral, instrumento de la subversión para degradar la moral de occidente, la izquierda veía en el homosexual una aberración contrarrevolucionaria producto de la degradación moral de las últimas etapas del capitalismo, que desaparecería en la sociedad liberada junto con el hambre, la desocupación y el analfabetismo. Es necesario explorar con mayor profundidad la experiencia concreta de los militantes homosexuales en las organizaciones de izquierda de los setenta, sin embargo, las referencias con las que contamos dan cuenta de un ambiente opresivo y homofóbico.

Anabitarte se afilia a la juventud comunista en 1959 y llega a ser responsable sindical de la zona centro, secretario del Círculo del Correo y responsable de propaganda y autodefensa del barrio, hasta que plantea a la dirección del partido el tema de la homosexualidad. Como respuesta, recibe el relevo de sus cargos y es enviado al psiquiatra del partido, quien le recomienda que para curarse, viaje a la Unión Soviética, ya que, según él, esta era "psicoterapéutica en sí misma". Tesitura similar sostenían en el ERP. Anabitarte, en su libro, cuenta la historia de Daniel, al cual la psicóloga de la organización lo tranquiliza diciéndole que su homosexualidad era una rebeldía equivocada, y que no se preocupara, ya que cuando tomasen el poder automáticamente se curaría (ANABITARTE, 2005, p.30-33).

Para la Juventud Peronista, la revolución sola no bastaba. En 1973, durante la primavera camporista, un grupo de militantes del FLH entre los que se encontraban Anabitarte, Perlongher y Adelaida Gigli concurren a una reunión con el equipo de abogados de la Juventud Peronista, que estaban preparando un pedido de amnistía para los presos políticos, para plantearles la posibilidad de incluir a los presos homosexuales. En medio de la reunión, una de las abogadas les plantea que no se preocupen, que cuando tomasen el poder iban a existir campos de reeducación para ellos ${ }^{7}$.

El caso extremo lo constituía Montoneros, organización que según Sebreli, habría fusilado en al menos dos oportunidades a homosexuales, por considerarlos apretables (SEBRELI, 1997, p. 337).

La única recepción cordial provino del trotskismo: El PST de Nahuel Moreno les ofrece una oficina en un sótano, pero con la condición de que ningún miembro del partido se enterara (SEBRELI, 1997, p.336). A pesar de la cautela, el trotskismo morenista fue la facción de la izquierda más proclive al trabajo con los homosexuales (INSAUSTI, en prensa).

Diez días después del retorno de Perón, la revista Así - de impresionante tirada para la época - dedica su tapa entera a cubrir la columna del FLH en la marcha a Ezeiza, incluyendo entre sus páginas una entrevista a tres miembros del FLH, quienes aprovechan la situación y utilizan cada una de las preguntas que les efectúa el cronista para identificarse con la izquierda peronista.

Sin embargo, la estrategia tiene efecto contrario al esperado. El coronel Jorge Osinde, responsable de la represión, aprovecha la asociación entre izquierda y homosexualidad, y pocos días después empapela la ciudad con carteles que acusaban a la Juventud Peronista y a los Montoneros de ser "homosexuales y drogadictos". La respuesta de la izquierda peronista fue machista y homofóbica. En las marchas y movilizaciones, empezó a cantarse: "No somos putos, no somos faloperos: somos soldados de Perón y Montoneros" (SEBRELI, 1997, p.337).

Un par de meses después, en septiembre de 1973, el FLH convoca a votar por el Justicialismo desde una solicitada publicada en la tapa de la revista Así. Sin embargo, el fracaso de la política de alianzas con la izquierda peronista era ya evidente.

\section{Tercer Momento. La revista Somos y la emergencia del discurso identitario. (1974-1976)}

Cuatro meses después de haber asumido, Perón restablece en sus funciones al ya retirado comisario Margaride (Oscar ANZORENA, 1998), encargado de la "Brigada de Moralidad" durante el "Onganiato" y máximo símbolo de la represión estatal a la sexualidad. Simultáneamente, la represión a los homosexuales superaba sus límites históricos y la Triple A comenzaba a sembrar el terror.

En diciembre de 1973 aparece la revista Somos, la cual se edita con un promedio de cincuenta páginas trimestralmente durante todo 1974 y convertido en un breve boletín en diciembre de 1975 y en enero de 1976.

Habitualmente considerada como el principal órgano de difusión del FLH, la revista Somos coincide en realidad con un momento de repliegue. Mientras el boletín Homosexuales era un

${ }_{7}^{7}$ Marcelo Benitez, entrevistado por Santiago Joaquín Insausti, Buenos Aires, 9 Sept. 2016. 
optimista compendio de proclamas políticas, en la cual el Frente se sentía empoderado como para enviar ultimátum llenos de ínfulas a las comisarias, presentar peticiones altaneras al ministro del interior, o impugnar con desdén a las organizaciones revolucionarias; la revista Somos es, en este nuevo contexto, una publicación de resistencia, melancólica y desilusionada, que empieza a ser consciente de la derrota.

Si el boletín Nuestro Mundo era un compendio de notas recortadas de la prensa masiva que intentaba discutir la criminalización de la homosexualidad, y el periódico Homosexuales era una misiva dirigida al resto de las organizaciones del campo popular, Somos estaba dirigida a los propios homosexuales con un criterio autodefensivo. Así, las notas enseñaban cómo reaccionar en caso de ser detenidos, informaban a los homosexuales sobre sus derechos e incluían una recopilación de las notas publicadas en la prensa sobre detenciones y razias.

Al mismo tiempo, en Somos, el FLH se repliega y se dedica a trabajar en la construcción de una identidad común y de una comunidad política.

Las revistas empiezan a intentar delinear una historia colectiva incorporando notas históricas: se conmemora la gran razia porteña de 1954, se relatan los escándalos en Uruguay de 1958 o se enumeran cuatro acciones judiciales contra sodomitas durante la Edad Media. En todos los números, se refieren las noticias de los grupos de homosexuales con las que se tiene contacto en otras regiones, transmitiendo la idea de que, aun fracasados los intentos de alianzas internas, no se está solo: otros intentos de organización homosexual estaban floreciendo en todo el mundo. El objetivo era forjar una identificación colectiva que generara lazos de solidaridad y que contribuya a superar la vergüenza y la culpa, problema que venía preocupando a los activistas hacía tiempo. En un documento interno, se analizaban los efectos subjetivos de la persecución cotidiana a partir del estudio de cómo la interiorización de la moral homofóbica tenía efectos devastadores sobre la subjetividad de las maricas. El documento relata la historia de Alberto, un homosexual que después de haber sufrido el hostigamiento de un grupo de policías "emergió, destrozado en su personalidad y como un individuo de existencia casi fantasmal (...) al punto de sentirse espiado y perseguido, de no confiar en nadie, de no sentirse vivir" (Análisis de la represión, S/D). Para enfrentar esto, el FLH, ya en 1972, había declarado que uno de sus objetivos principales era "devolver a los homosexuales el gusto por la vida" (Boletín, 1972). En la revista Somos se dará una vuelta de tuerca al asunto, incorporándose por primera vez el dispositivo del "orgullo". En el número 3, en "Los homosexuales somos hermosos", se consigna:

Los homosexuales típicamente carecemos, como cualquier grupo oprimido, de una identidad satisfactoria. (...) Debemos pues construir una identidad homosexual, reivindicando en primer término nuestra condición de seres humanos con los mismos derechos de cualquier otro, exenta de noción de enfermedad o inferioridad o anormalidad. Y en segundo lugar, debemos reivindicaron orgullosamente como homosexuales, tirando de una vez por la borda el tremendo peso de la vergüenza y la culpa que nos han hecho sentir. (Somos, 1974, p. 1)

En 1969, en el boletín Nuestro Mundo se entrevistaba a un homosexual el cual sostenía que un homosexual no podía ser feliz y que las relaciones entre homosexuales no podían ser duraderas. En 1974, en la Somos 3 se efectúa otra entrevista, muy similar, a otro homosexual. En este caso, las respuestas son opuestas:

Charlando, estando en el Frente, llegue a comprender que me siento feliz de ser homosexual. (...) He llegado a la conclusión de que no soy un enfermo, un condenado o un monstruo. Me siento feliz. A partir de sentir, vivir una relación nueva, no vergonzante con otros homosexuales, leer literatura liberacionista, participando en el grupo en el Frente, reflexionando sobre el ser humano y su naturaleza, me siento como asumiendo naturalmente mi homosexualidad. Puedo afirmar que siento placer en ser homosexual. (Somos, 1974, p.19)

En línea con este proyecto, aparece por primera vez la subjetividad y la cultura de las locas: por primera vez las poesías, los cuentos, las crónicas y los dibujos de las maricas tienen lugar en la revista. Las detenciones y las experiencias carcelarias son relatadas ahora en primera persona y ya no desde la crónica periodista. Por primera vez aparecen las esperanzas y los miedos de las locas, pero también los espacios de resistencia lúdica, las parties y las fiestas, la amistad y el amor.

La cultura de las locas es reivindicada y celebrada. En contraste con el alto grado de sofisticación teórica de los documentos anteriores, Somos les habla a las maricas en su propio idioma. Muchas notas están escritas en argot marica o respetando sus "nombres de guerra". El número 4, por ejemplo, incluye una recopilación con cientos de formas de referirse a la práctica del fellatio o del sexo anal, con entradas como "hacer el frufrú", "sancochar la mandropa" y "tirar del fideo" (Somos, 1974, pp.16).

A diferencia de las revistas anteriores, constituidas únicamente por texto, Somos lleva a modo de portada una ilustración que representa y celebra el mundo y la cultura de las locas. Una canasta de mimbre con rosas, una marica con el pelo colonizado por las flores y el follaje, un 
adolescente andrógino de pelo largo y torso desnudo. A diferencia del periódico Homosexuales, en que los homosexuales se presentaban racionales y combativos, como aliados dignos de las organizaciones en la lucha revolucionaria, Somos rescata la sensibilidad y la emotividad de la subcultura homosexual porteña.

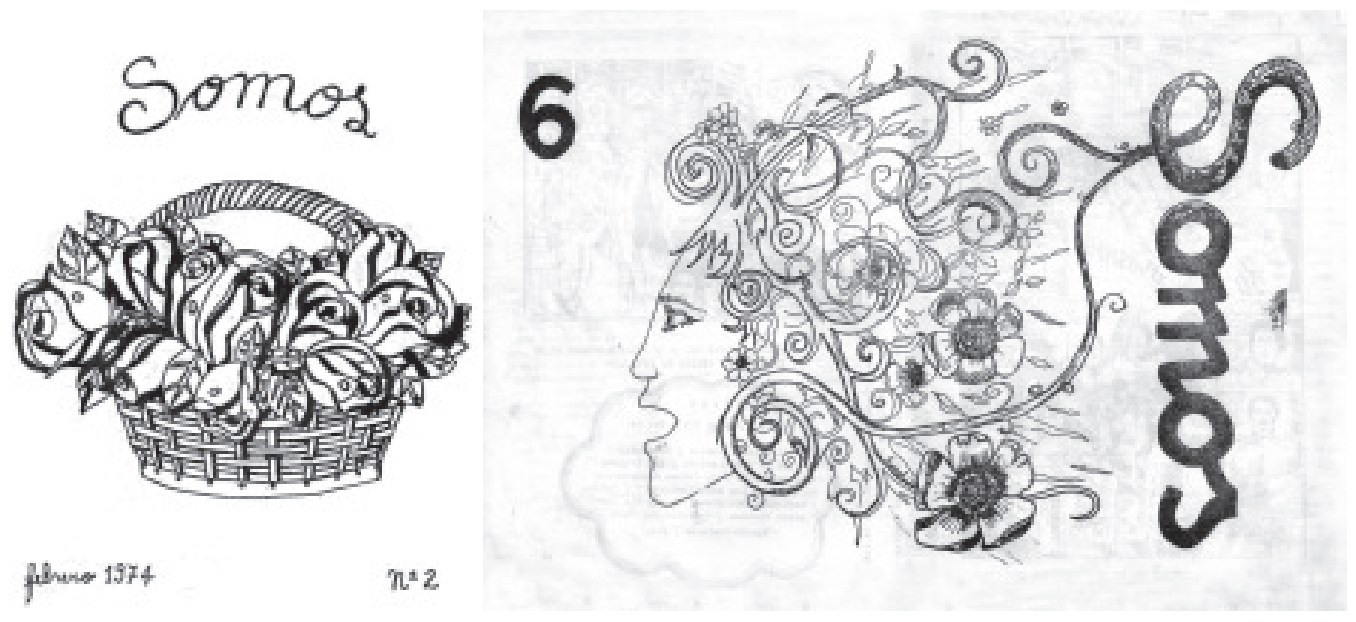

Figura 1: Portadas del número 2 (der.) y 6 (izq.) de la revista Somos.

A partir de la década del noventa, las denuncias sobre los límites de la representación (Judith BUTLER, 1990) enfrentarán en el campo de la diversidad sexual a dos modos de pensar el sujeto: a los modelos tradicionales de política identitaria se le contraponerá una política queer que no entenderá a las identidades como núcleos ontológicos sino como constructos contingentes (Joshua GAMSON, 1995). En Argentina, la cronología del movimiento LGTB se re-inventará en sintonía con estas tensiones. Así, a las políticas de las organizaciones de los ochentas basadas en el concepto de "comunidad minoritaria" y en el dispositivo del orgullo se enfrentaría la políica radical del FLH, deslindada de cualquier noción de sujeto homosexual fija. Sin embargo, si bien la revista Somos era heterogénea en su línea editorial y es clara en las notas más teóricas del boletín ${ }^{8}$ la línea teórica del grupo Eros que se había plasmado en lemas como "no hay que liberar a los homosexuales, hay que liberar lo homosexual en cada persona" (Guillermo OLIVERA, 1999, p. 146), también es cierto que estas revistas empiezan a desplegar el dispositivo del orgullo y la necesidad de construir una definición estable de homosexualidad mucho tiempo antes que lo que las cronologías oficiales sostienen.

Somos también permite ver en sus sucesivas emisiones el progresivo desengaño del FLH con el Peronismo. A sesenta días de asumido Perón, el número 1 de la revista da cuenta del recrudecimiento de la represión y denuncia la reincorporación de Margaride. Ya se percibe la pérdida de la esperanza en el peronismo que se había puesto de manifiesto en Homosexuales. La policía ya no era la misma a la que habían enviado aquella carta conciliadora, y se aclara que "ninguna ley ni reforma será suficiente para que (...) [esta] deje de perseguirnos" (Somos, 1973, p.8).

En febrero de 1974, el segundo número registraba el creciente temor por el avance de la política represiva del gobierno. Varios artículos denuncian el crecimiento de la brutalidad policial, cuya similitud con los gobiernos anteriores era tal que sólo faltaba Onganía.

En el número 4 se incrementa la preocupación por la represión. Uno de los artículos anuncia que "cada uno de nosotros tiene un amigo preso" (Somos, 1974, p.1). Se advertía que la muerte de Perón implicaba un cambio de rumbo y que se estaban produciendo una serie de atentados provocados por grupos parapoliciales.

A fines del año 1974, el FLH no solo había roto de manera abierta con el peronismo, sino que ahora identificaba que este régimen era el mismo que había originado el pico represivo más importante de todo el siglo: la razia de 1954, cuyo aniversario se registraba en el número 5 de la revista. Allí se publica un comunicado redactado tras la muerte de Perón, que constituye un balance del resultado de la apuesta al peronismo. Son reivindicadas la apuesta al peronismo y la participación en las marchas del 25 de mayo y del 20 de junio por la necesidad de unión con todos los sectores en lucha; pero también se denuncia el aumento exponencial de la represión durante el año que duró la presidencia de Perón, así como la avanzada "fascista" contra los militantes populares.

${ }^{8}$ En "La represión sexual en acción" por ejemplo, se seguia declamando este potencial de la homosexualidad para hacer estallar todos los devenires sexuales: "un homosexual manifiesto despierta la homosexualidad latente de los otros, el conjunto de la sexualidad dormida" (Somos, 1975, p. 39) 
Un punto de inflexión lo constituye la publicación en la revista de la ultraderecha peronista EI Caudillo, del editorial "Acabar con los homosexuales" en febrero de 1975, el cual acusa al marxismo de utilizar la homosexualidad para "enviciar y corromper al pueblo" y llama a formar brigadas que recorran los barrios dando caza a los homosexuales para "encerrarlos o matarlos" (EI Caudillo, 1975).

El FLH no se queda quieto ante la amenaza de El Caudillo. Emprenden una campaña de denuncia internacional ${ }^{9}$ y logran que el editorial de EI Caudillo sea condenado por varios medios homófilos extranjeros. En otra nota aparecida en la revista II Fuori declaran no haber permanecido inertes: "Hemos respondido (al editorial) con una manifestación pública, escritos murales, medidas de precaución. El F.L.H. argentino no fue debilitado, ni nosotros fuimos intimidados" (II Fuori, 1975). Paralelamente, hacen circular un documento entre las bases, advirtiendo de la situación y llamando a la unidad, como única forma de resistir al fascismo. En la interpretación del FLH, la estrategia de la derecha se basaba en "asociar a la izquierda y al movimiento obrero con la homosexualidad, mientras esparcía simultáneamente un pánico antihomosexual como medio de combatir a las fuerzas progresistas" (MCCASKELL, 1976).

En enero de 1976 se publicaba el último número de Somos. La menor cantidad de páginas da cuenta del deterioro de la organización que atravesaba dificultades para organizarse en el contexto de la vigilancia extrema y del estado de sitio.

La última aparición pública es una nota en el diario Crónica titulada "Extraña protesta: Homosexuales se quejan de persecución”, publicada el 11 de febrero de 1976. Un mes después, con la toma del poder por parte de las Fuerzas Armadas y el incremento de la vigilancia urbana y el terror, sumado a que muchos activistas del FLH también eran militantes de partidos de izquierda y deberían exiliarse, exigió que el Frente dejara de efectuar reuniones y se disolviera de hecho.

El 1 de octubre de 1976, Bodypolitics da cuenta de la imposibilidad de celebrar reuniones o realizar actividades públicas, e informa que, a pesar de esto, cincuenta miembros del FLH siguen operando en la clandestinidad. Sara Torres, sin embargo, en una entrevista, señala que la posibilidad de reunirse, más allá de los encuentros casuales en fiestas o reuniones de amigos, era nula.

En octubre de 1981, Anabitarte y su pareja son entrevistados por un periodista estadounidense en Barcelona. En ella, uno de los principales referentes del frente puede atisbar un balance de los intentos de articular con la izquierda peronista:

Nos encontrábamos atrapados entre el diablo -la profundamente fascista dictadura militar- y la posibilidad de un nuevo régimen que podría ser benéfico para la mayoría, pero que aun así seguiría siendo nuestro opresor (...) Por un lado era esencial unirse con cualquier fuerza posible que luche contra el régimen represivo. Es elemental que el derrocamiento de una dictadura militar es la única forma para cualquiera de obtener derechos. En este proceso el Frente se influencio bastante de los Montoneros que eran la mayor fuerza en la oposición y resistencia. Es aquí donde comenzó el problema. Antes, el Frente era difícilmente identificable como un movimiento para la liberación de lesbianas y gays, parecía más bien otra agrupación política. Mientras tomaba un rol más militante, los gays que no estaban muy politizados o que no se identificaban con el peronismo de izquierda o con las organizaciones armadas se alejaron. (FORGIONE, 1982)

La estrategia era politizar a las masas de homosexuales por un lado y sensibilizar a la izquierda sobre la revolución sexual, por otro. Pero los intentos de articular homosexualidad y activismo radical estuvieron signados por las tensiones tanto entre el FLH y las demás organizaciones de izquierda, como al interior del frente y entre el frente y sus bases. Distanciadas de las bases, traicionadas por las organizaciones de izquierda y acorraladas por la represión, el proyecto del FLH se obtura aún mucho antes del golpe de estado del 24 de marzo de 1976.

\section{Conclusiones}

La mayor parte de la historiografía sobre el FLH ha tendido a enfocarse en el análisis discursivo de la revista Somos, el cual, al focalizar solamente en un período de la organización, pierde de vista la capacidad de adaptación que el frente desplegó en el marco de una coyuntura política extremadamente cambiante. Como parte integrante del abanico de un campo popular que se amplificó en cuestión de años y como antagonista de un Estado que cambiaba abruptamente sus estrategias para gestionar la conflictividad social, el Frente no es entendible si no es el marco de una lectura cruzada con la historia social y política del período.

A pesar de que parezca contraintuitivo, no es casual que, en 1967, en el contexto de la resistencia peronista a la proscripción, cuando el grueso de la vida política estaba organizado alrededor de los sindicatos, Nuestro Mundo haya emergido como una organización sindical ligada al mundo del trabajo. O que luego, cuando la política se organizaba alrededor de la nueva izquierda, el FLH haya emergido dentro de ésta entendiendo la liberación sexual, la revolución

${ }^{9}$ Las amenazas del caudillo son mencionadas en varias publicaciones homófilas extranjeras (II Fuori, 1975; The Body Politics, 1975). En marzo, el semanario Pa'fuera (1975) de San Juan de Puerto Rico denuncia la escalada represiva y la "tendencia a la fascitizacion del estado" argentino. 
social y la lucha contra el autoritarismo como imbricadas e indisociables. En este marco, la apuesta estratégica al peronismo de izquierda era, contextualmente, indiscutible. Durante las décadas del sesenta y setenta Argentina estuvo sujeta a cambios repentinos que constantemente modificaban el escenario político. Íntimamente ligado a estos vaivenes, el FLH cambiaba sus estrategias de acuerdo con su inserción en este contexto fluctuante. Intentaron actuar en los sindicatos, aliarse con diferentes sectores de la izquierda, trazar lazos con el feminismo y las contraculturas urbanas, hacer lobby ante el Estado durante el camporismo, y sólo cuando todas estrategias fracasaron es que el grupo se volcó a politizar a las bases a través de Somos.

La atención en el contexto político y social también permite entender como ciertos rasgos supuestamente contra intuitivos del frente, tienen en realidad sentido en un marco estructural más amplio.

Podría resultar controversial que Nuestro Mundo avalase la patologización de la homosexualidad. Sin embargo, esto es entendible si se percibe que el grupo estaba luchando contra la criminalización en un marco de sentidos que tenía en la dicotomía criminalización/ patologización el único marco interpretativo para la homosexualidad. También puede resultar contradictorio el hecho de que el frente tendiera lazos en vistas a incidir en el estado burgués, al tiempo que estaba intentando tejer redes con las organizaciones de la izquierda revolucionaria. Sin embargo, las lógicas de esta doble apuesta se revelan al considerar las particularidades del Estado camporista y el nivel de inserción que no solo los homosexuales, sino también otras facciones de la izquierda radical aspiraban a tener en el Estado. Finalmente, en la revista Somos puede resultar paradójica la convivencia del discurso anti-identitario del grupo Eros, que entendía a la sexualidad alienada como un contínuum a ser liberado conjuntamente, con los intentos de construir una subcultura homosexual específica en relación a una nueva identidad gay honrosa. Sin embargo, esta disyuntiva es fácilmente legible si se percibe que las sofisticadas teorizaciones del freudomarxismo debían conciliarse con bases de homosexuales que no tenían formación teórica alguna y exigían con urgencia marcos simbólicos asequibles con los cuales combatir las vejaciones de las que eran objeto por parte de las representaciones hegemónicas sobre la homosexualidad.

El Frente de Liberación Homosexual no puede pensarse desligado de los procesos sociales ni de los marcos macro políticos del período. Es solamente en este escenario que se puede aprehender la singularidad de una experiencia política extremadamente heterogénea y compleja.

\section{Agradecimientos}

Agradezco a Zelmar Acevedo, Sergio Pérez Álvarez, Héctor Anabitarte, Marcelo Benítez, Marcelo Ferreyra, Jorge Giacosa y Sara Torres su invaluable colaboracion. Este trabajo fue posible gracias a que que fui favorecido con la Phil Zwickler Memorial Research Grant, otorgada por la Cornell University Library's Human Sexuality Collection y con la Wallis Annenberg Research Grant otorgada por la University of Southern California. Mi investigación forma parte del proyecto "Diversidad de género, masculinidad y cultura en España, Argentina y México" (FEM2015-69863P MINECO-FEDER) del Ministerio de Economía y Competitividad de España y del Proyecto "Perspectivas teórico-metodológicas sobre política, género, sexualidad y salud en América Latina" de la Universidad de Buenos Aires y fue realizada en el marco de una estancia posdoctoral en la Facultad de Filosofía y Letras de la misma universidad.

\section{Bibliografía}

ANABITARTE, Héctor. Nadie olvida nada. Aranjuez: Ediciones Impublicables, 2005.

ANABITARTE, Héctor. Estrechamente vigilados por la locura. Barcelona: Hacer, 1982.

ANZORENA, Oscar. Tiempo de violencia y utopía. Buenos Aires: Colihue, 1998.

BELLUCCI, Mabel. Historia de una desobediencia. Buenos Aires: Capital Intelectual, 2014.

BEN, Pablo; INSAUSTI, Santiago Joaquin. "Dictatorial Rule and Sexual Politics in Argentina: The Case of the Frente de Liberación Homosexual, 1967-1976". Hispanic American Historical Review, Durham, v. 97, n. $2,2017$.

BUTLER, Judith. El género en disputa. Madrid: Paidós, 1990.

COSSE, Isabella. Pareja, sexualidad y familia en los años sesenta. Buenos Aires: Siglo Veintiuno, 2010.

FERNÁNDEZ GALEANO, Javier. "Cartas desde Buenos Aires: el movimiento homosexual argentino desde una perspectiva transnacional". Latin American Research Review, v. 54, n. 3, En prensa. 
FORGIONE, Steve. "Living in Exile; The Story of Gay Liberation in Argentina". Gay Community News, Boston, p. 7, 20 de febrero de 1982.

GAMSON, Joshua. “¿Deben autodestruirse los movimientos identitarios?”. En: MÉRIDA, Rafael (ed.). Sexualidades transgresoras. Barcelona: Icaria, 1995.

GRUPO CATÓLICOS. A los compañeros del Frente de Liberación Homosexual. S/F. Documento interno.

GRUPO CATÓLICOS. La homosexualidad y los cristianos. S/F. Documento interno.

GRUPO EROS. “La represión sexual en acción”. Somos, Buenos Aires, n. 5, 1975.

INSAUSTI, Santiago Joaquín. Una mirada sobre las publicaciones del Frente de Liberación Homosexual. En: IV JORNADAS DE HISTORIA DE LAS IZQUIERDAS, Buenos Aires, CEDINCI. Actas, 2007.

INSAUSTI, Santiago Joaquín, "Los cuatrocientos homosexuales desaparecidos: memorias de la represión estatal a las sexualidades disidentes en Argentina”. En: D’ANTONIO, Debora (Comp.) Deseo y represión: Sexualidad, género y Estado en la historia reciente argentina. Buenos Aires: Ediciones Luxemburg, 2015.

INSAUSTI, Santiago Joaquín, “¿Hedonistas o revolucionarios? Política homosexual radical e izquierda trotskista en Argentina y Brasil (1967-1983)". Mora, Buenos Aires, Instituto Interdisciplinario de Estudios de Género (Universidad de Buenos Aires), en prensa.

MALVA. Mi recordatorio. Buenos Aires: Rojas, 2011.

MECCIA, Ernesto. El tiempo no para. Buenos Aires: EUDEBA, 2017.

LENNARD, Patricio. "Entrevista a Juan José Sebreli". Soy, Buenos Aires, 24 de julio de 2009.

MCCASKELL, Tim. "Gay Life and the Liberation Struggle in Argentina: 'We Will Conquer a Space Filled with Light'”. Body Politic, Toronto, p. 9, octubre de 1976.

MANZANO, Valeria. "Sexualizing Youth: Morality Campaigns and Representations of Youth in Early 1960s Buenos Aires”. Journal of History of Sexuality, v. 14, n. 4, p. 433-461, Octubre de 2005.

NEWTON, Huey. "A letter from Huey Newton". En: We Are Everywhere. London: Routledge, 1997.

OLIVERA, Guillermo. "Políticas de la representación homosexual en la Argentina". En: FORASTELLI, Fabricio; TRIQUELL, Ximena (Eds). Las marcas del género. Córdoba: UNC, 1999.

PERLONGHER, Néstor. "Historia del Frente de Liberación Homosexual de la Argentina". En: Prosa plebeya. Buenos Aires: Colihue, 1997.

PUIG, Manuel. El beso de la mujer araña. Barcelona: Seix Barral, 1976.

PUIG, Manuel. La traición de Rita Hayworth. Barcelona: Seix Barral, 1968.

PUIG, Manuel. Boquitas pintadas. Barcelona: Seix Barral, 1969.

RAPISARDI, Flavio y MODARELLI, Alejandro. Fiestas, baños y exilios. Buenos Aires: Sudamericana, 2001.

SEBRELI, Juan José. "Historia Secreta de los Homosexuales en Buenos Aires". En: Escritos sobre escritos, ciudades bajo ciudades. Buenos Aires: Sudamericana, 1997.

SEBRELI, Juan José. Buenos Aires, vida cotidiana y alienación. Buenos Aires: Siglo Veinte, 1964.

SIMONETTO, Patricio. Entre la injuria y la revolución. Bernal: UNQ, 2017.

SIMONETTO, Patricio. "Movimientos de liberación homosexual en América Latina". Iberoamericana, XVII, n. 65, p. 157-177, $2017 \mathrm{~b}$.

VESPUCCI, Guido. "Explorando un intrincado triángulo conceptual: homosexualidad, familia y liberación en los discursos del Frente de Liberación Homosexual de Argentina (1971-1976)". Historia Crítica, n. 43, p. 174-197, enero-abril 2011.

VESPUCCI, Guido. Homosexualidad, familia y reivindicaciones: De la liberación sexual al matrimonio igualitario. Buenos Aires: UNSAM, 2017. 


\section{Otras fuentes}

S/A. "Buenos Aires". Fuori!, Turin, 1975.

S/A. "Homosexualidad histórica: Mesopotamia y Judea". Homosexuales, Buenos Aires, p. 2, julio. 1973.

S/A. "Letter from Argentina". Body Politics, Toronto, p. 8, 1 de febrero. 1975.

S/A. “Lettera dall'Argentina”. Fuori!, Turin, invierno. 1973.

S/A. Somera Cronología del F.L.H. S/F. Documento.

S/A. "Acabar con los homosexuales", El Caudillo, Buenos Aires, febrero. 1975.

S/A. "¿Varón o hembra? Búsqueda de la enigmática sustancia X". Nuestro Mundo, Buenos Aires, año 3, n. 4, p. 4, diciembre. 1970.

S/A. Análisis de la represión policial y del comportamiento homosexual ante la misma. S/F. Documento interno.

S/A. "Cada uno de nosotros tiene un amigo preso". Somos, Buenos Aires, n. 4, agosto/septiembre. 1974.

S/A. Carta a Diputado electo por la Capital Federal. marzo 1973. Documento Interno.

S/A. "Cerremos Filas". Así, Buenos Aires, año XI, n. 521, p. 1, 21 septiembre. 1973.

S/A. "Cine: Miserias y esplendores". Nuestro Mundo, Buenos Aires, año 3, n. 4, p. 2, diciembre. 1970.

S/A. "Comunicado". Somos, Buenos Aires, n. 1, diciembre. 1973.

S/A. “Declaración”. Homosexuales, Buenos Aires, p. 3, julio. 1973.

S/A. "Devolver a los homosexuales el gusto por la vida". Boletín Del FLH, Buenos Aires, mayo. 1972.

S/A. "Homosexuales". Quinta Rueda, Santiago de Chile, p. 2, agosto. 1972.

S/A. "Homosexualidad: ¿Quiénes son?". Panorama, Buenos Aires, 2 de mayo. 1974.

S/A. "Las voces clandestinas". Panorama, Buenos Aires, 24 de agosto. 1972.

S/A. "Los homosexuales somos hermosos". Somos, Buenos Aires, n. 3, mayo. 1974.

S/A. "Los oprimidos no se convertirán en opresores". Homosexuales, Buenos Aires, p. 3, julio. 1973.

S/A. “Los términos sexuales". Somos, Buenos Aires, n. 4, agosto/septiembre. 1974.

S/A. "Nueva Experiencia". Nuestro Mundo, Buenos Aires, año 3, no 4, p.3, diciembre. 1970.

S/A. "Petitorio". Homosexuales, Buenos Aires, p. 1, Julio. 1973.

S/A. "Recrudece la opresión anti-gay en Argentina". Pa'fuera!, San Juan de Puerto Rico, Marzo. 1975.

S/A. "Reportaje". Somos, Buenos Aires, n. 3, mayo. 1974.

Santiago Joaquin Insausti (sinsau@gmail.com) es sociólogo y doctor en Ciencias Sociales por la Universidad de Buenos Aires, donde también se desempeña como Profesor. Su campo de estudios se enfoca en la historia reciente de la sexualidad en Latinoamérica. Ha publicado artículos en diversas compilaciones y revistas científicas y presentado sus trabajos en congresos nacionales e internacionales. Actualmente se encuentra investigando cómo los cambios en la identidad homosexual han delineado las transformaciones de las políticas socio-sexuales en Argentina en los últimos 50 años. 


\section{COMO CITAR ESSE ARTIGO DE ACORDO COM AS NORMAS DA REVISTA}

INSAUSTI, Santiago Joaquin. "Una historia del Frente de Liberación Homosexual y la izquierda en Argentina". Revista Estudos Feministas, Florianópolis, v. 27, n. 2, e554280, 2019.

\section{CONTRIBUIÇÃO DE AUTORIA}

Não se aplica

\section{FINANCIAMENTO}

Phil Zwickler Memorial Research Grant - Cornell University Library's Human Sexuality Collection. Wallis Annenberg Research Grant - University of Southern California.

Proyecto "Diversidad de género, masculinidad y cultura en España, Argentina y México" (FEM201569863-P MINECO-FEDER) del Ministerio de Economía y Competitividad de España.

Proyecto "Perspectivas teórico-metodológicas sobre política, género, sexualidad y salud en América Latina" de la Universidad de Buenos Aires.

\section{CONSENTIMENTO DE USO DE IMAGEM}

Não se aplica

APROVAÇÃO DE COMITÊ DE ÉTICA EM PESQUISA

Não se aplica

\section{CONFLITO DE INTERESSES}

Não se aplica

LICENÇA DE USO

Este artigo está licenciado sob a Licença Creative Commons CC-BY Internacional. Com essa licença você pode compartilhar, adaptar, criar para qualquer fim, desde que atribua a autoria da obra.

\section{HISTÓRICO}

Recebido em 27/1 1/2017

Reapresentado em 09/1 1/2018

Aprovado em 18/12/2018

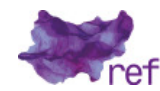

